\title{
A randomized cross over trial of oral nifedipine and intravenous labetalol in pregnant women with severe pre-eclampsia and eclampsia
}

\author{
Kirtan Krishna $^{1 *}$, N. Shailaja ${ }^{1}$, B. Shyamasundara Bhat ${ }^{1}$, L. Krishna ${ }^{1}$, Namrata $^{2}$
}

\begin{abstract}
${ }^{1}$ Department of Obstetrics and Gynecology, PES Institute of Medical Sciences and Research, Kuppam, Andhra Pradesh, India

${ }^{2}$ Department of Obstetrics and Gynecology, SDM College Medical Sciences and Hospital, Dharwad, Karnataka, India
\end{abstract}

Received: 12 January 2019

Accepted: 06 February 2019

\author{
*Correspondence: \\ Dr. Kirtan Krishna, \\ E-mail: kirtank1@gmail.com
}

Copyright: () the author(s), publisher and licensee Medip Academy. This is an open-access article distributed under the terms of the Creative Commons Attribution Non-Commercial License, which permits unrestricted non-commercial use, distribution, and reproduction in any medium, provided the original work is properly cited.

\begin{abstract}
Background: The aim of treatment of severe pre-eclampsia and eclampsia is to quickly bring about a smooth reduction in blood pressure to levels that are safe for both mother and baby but avoiding any sudden drops. There are not many studies comparing nifedipine and labetalol for this purpose. Authors conducted this study with the aim of comparing their efficacy in reducing maternal blood pressure.

Methods: It was a cross over trial with 30 patients in each group conducted at a tertiary care hospital. 60 pregnant women were randomized to receive nifedipine (20mg loading dose followed by $10 \mathrm{mg}$ tablet, orally, up to maximum of five doses) or intravenous labetalol (in an escalating dose regimen of 20, 40, 80, 80 and $80 \mathrm{mg}$ ) every 20 minutes until the target blood pressure of $150 / 100 \mathrm{mmHg}$ was achieved. Crossover treatment was affected if the initial treatment regimen was unsuccessful after $20 \mathrm{~min}$ of the last dose of the drug in the respective groups.

Results: The mean time to achieve the target blood pressure was $32.0 \pm 18.64$ minutes (mean \pm SD) in nifedipine group as compared with $37.04 \pm 16.36$ minutes in those receiving labetalol $(\mathrm{P}=.002)$. In the nifedipine group $63.3 \%$ required only one dose compared to $36.6 \%$ in the labetalol group. Only two women in the nifedipine group required maximum number of doses that is five doses. Cross over treatment was required by $10 \%$ of patients in the labetalol group and none in the nifedipine group.

Conclusions: This study shows that oral nifedipine is more effective than intravenous labetalol in rapid control of hypertension in severe pre-eclampsia and eclampsia.
\end{abstract}

Keywords: Eclampsia, Hypertension, Labetalol, Nifedipine, Pre-eclampsia

\section{INTRODUCTION}

Preeclampsia is a pregnancy-specific multisystem disorder of unknown etiology. The disorder affects approximately 5 to 7 percent of pregnancies 1 and is a significant cause of maternal and fetal morbidity and mortality. Pre-eclampsia accounts for $12-18 \%$ of maternal mortality. ${ }^{1,2}$

There is general consensus that maternal risk is decreased by antihypertensive treatment that acutely lowers very high blood pressure. ${ }^{3-5}$ The aim of treatment is to quickly bring about a smooth reduction in blood pressure to levels that are safe for both mother and baby but avoiding any sudden drops that may in themselves cause problems such as dizziness or fetal distress. ${ }^{6}$ Two short acting antihypertensive agents- labetalol and nifedipine-are commonly used to control acute, very high blood pressure in women with severe hypertension in pregnancy. ${ }^{3}$ Both agents have their proponents and detractors. Short acting nifedipine has the clinical advantage of being able to be given as required by 
midwives or nurses in the absence of a doctor. However, uncertainty exists about how safe short acting calcium channel blockers are for the mother. ${ }^{7}$ Two case reports of transient neuromuscular weakness in patients taking nifedipine and magnesium sulphate have caused concern about concomitant use of these agents. ${ }^{8,9}$

Labetalol has been used extensively in pregnancy and has a favourable side effect profile. However, specific concern has been raised about the risk of neonatal bradycardia with parenteral labetalol. ${ }^{10}$ Given the recent emergence of newer or alternative first-line agents in the management of severe hypertension in pre-eclampsia and eclampsia, a study to compare the efficacy of nifedipine and labetalol is warranted.

To date, there have not been many randomized clinical trials comparing these two agents in pregnancy. The objective of our investigation is to compare the efficacies of oral nifedipine and intravenous labetalol in the management of severe preeclampsia and eclampsia in pregnancy. Primary objective of the present study was to evaluate the time interval required to achieve the therapeutic blood pressure goal of $<150 \mathrm{~mm} \mathrm{Hg}$ systolic and $<100 \mathrm{~mm} \mathrm{Hg}$ diastolic. Secondary outcomes analysed included agent failure, urinary output, any adverse maternal effects and abnormal fetal heart rate patterns, 5minute Apgar scores of $<7$.

\section{METHODS}

A randomized cross over study was conducted among 60 parturients with severe Pre-eclampsia, and eclampsia at PESIMSR, Kuppam over a period of 1year from 1st September 2015 to 31st August 2016.Ethical clearance was obtained from the institutional ethical committee. During the study period, parturients aged $18-35 y$ rs old with gestational age $>28$ weeks gestation admitted for monitoring of labor and delivery at PESIMSR, Kuppam with $\mathrm{BP}>160 / 110 \mathrm{~mm} \mathrm{Hg}$ were recruited for the study after taking an informed consent.

\section{Exclusion criteria}

- Women with a history of atrial-ventricular heart block, moderate-to-severe bronchial asthma and exposure to either study medication within 24 hours of enrolment.

To detect a $20 \%$ difference in the time interval required to achieve the therapeutic blood pressure goal, with alpha $=.05$ and beta $=0.1$, and a predetermined significance of 0.001 by using nMaster 2.0, Biostatistics CMC software it was determined that 25 patients would be needed in each treatment group. To account for $12.5 \%$ cross over in each group, 30 patients were taken in each group.

The subjects were randomised into the two groups. A computer-generated sequence was used for the randomisation and sealed opaque envelopes were prepared for allocation concealment. These envelopes were entrusted to the labour room in charge who administered the drug specified on the envelope. Patients randomized to oral nifedipine received $20 \mathrm{mg}$ initially, with repeated doses of $10 \mathrm{mg}$ every 20 minutes for up to a maximum of 5 doses or until the therapeutic blood pressure goal of $<150 \mathrm{~mm} \mathrm{Hg}$ systolic and $<100 \mathrm{~mm} \mathrm{Hg}$ diastolic was achieved whichever was earlier. Patients randomized to intravenous labetalol received $20 \mathrm{mg}$ initially, followed by escalating doses of $40 \mathrm{mg}, 80 \mathrm{mg}$, $80 \mathrm{mg}$, and then $80 \mathrm{mg}$ every 20 minutes until the therapeutic goal is achieved or for a maximum of 5 doses. If the therapeutic goal was not achieved after 5 doses, crossover to the alternative study medication was done.

Once the therapeutic goal was achieved maintenance was with Capsule Nifedipine 10mg 6th hourly or Tablet labetalol 100mg 8th hourly.

\section{Study design}

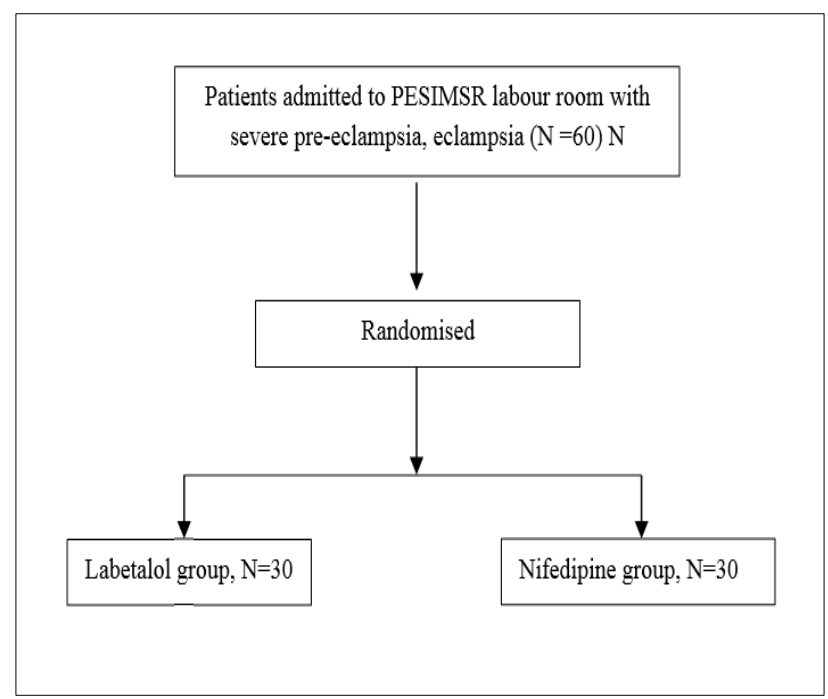

Figure 1: Illustrating the study design through the flow chart.

Demographic and standard laboratory data was collected on admission. Blood pressure was obtained with a mercury sphygmomanometer, taking the fifth Korotkoff sound for the diastolic blood pressure. Once patients were enrolled, vital signs were recorded with a sphygmomanometer and pulse oxymeter every 15 minutes and continued for up to 3 hours after enrolment. All measurements were recorded with the parturient in the lateral recumbent position and with the head of the bed elevation not exceeding $15^{\circ}$. Fluid restriction was done to reduce the risk of fluid overload in the intrapartum and postpartum periods. Total fluid was limited to $80 \mathrm{ml} /$ hour or $1 \mathrm{ml} / \mathrm{kg} /$ hour. Over the last 20 years, pulmonary oedema has been a significant cause of maternal death. ${ }^{11}$

Proteinuria was assessed by a screening test which was a visual dipstick assessment. A two plus dipstick 
measurement was taken as evidence of proteinuria. While it has to be acknowledged that there is poor predictive value from urine dipstick testing, 12 approximate equivalence is $1+=0.3 \mathrm{~g} / \mathrm{l}, 2+=1 \mathrm{~g} / \mathrm{l}$ and $3+=3 \mathrm{~g} / \mathrm{l}$. False negative as well as false positive rates are recorded with the use of visual dipstick assessment. ${ }^{12-14}$ Urine output volumes was collected and recorded with a Foleys catheter for 24 hours after the initial dosing.

Continuous fetal heart rate monitoring was performed on all undelivered patients, and any maternal side effects or fetal heart rate abnormalities were recorded. Additional neonatal outcomes evaluated included 5-minute APGAR scores of $<7$.

\section{Statistical analysis}

Descriptive and inferential statistical analysis has been carried out in the present study. Results on continuous measurements are presented on Mean \pm SD (Min-Max) and results on categorical measurements are presented in Number (\%). The time to control of BP between the 2 groups has been compared. Chi-square/ Fisher Exact test has been used to find whether there is any significant difference between the two drug groups in this respect since the variables were normally distributed.

\section{RESULTS}

Table 1 shows the baseline characteristics of the participants stratified according to their randomisation. The demographic data was statistically similar in the two study groups. The median age group was 23-25 years. Authors did not have many subjects in extremes of age group which would otherwise affect the maternal and perinatal outcome.

Table 1: Demographic data of the two treatment groups.

\begin{tabular}{|c|c|c|c|}
\hline Variable & Nifedipine & Labetalol & Statistical significance (P value) \\
\hline Age (years) & $25.20 \pm 4.22$ & $23.67 \pm 3.45$ & 0.129 \\
\hline \multicolumn{3}{|l|}{ Parity } & \multirow{3}{*}{0.616} \\
\hline Primi & $56.7 \%$ & $53.3 \%$ & \\
\hline Multi & $43.3 \%$ & $46.7 \%$ & \\
\hline \multicolumn{3}{|c|}{ Socio economic status } & \multirow{3}{*}{1.000} \\
\hline Low & $96.7 \%$ & $100.0 \%$ & \\
\hline Upper middle & $3.3 \%$ & 0 & \\
\hline Booked & $36.7 \%$ & $43.3 \%$ & \multirow{2}{*}{0.918} \\
\hline Unbooked & $6.7 \%$ & $3.3 \%$ & \\
\hline Rural & $53.3 \%$ & $50.0 \%$ & \multirow{2}{*}{0.918} \\
\hline Urban & $3.3 \%$ & $3.3 \%$ & \\
\hline \multicolumn{3}{|l|}{ Gestational age } & \multirow{5}{*}{0.167} \\
\hline$<32$ weeks & $6.7 \%$ & $10 \%$ & \\
\hline $32-37$ weeks & $20 \%$ & $23.3 \%$ & \\
\hline $37-40$ weeks & $50 \%$ & $63.3 \%$ & \\
\hline$>40$ weeks & $23.3 \%$ & $3.3 \%$ & \\
\hline \multicolumn{3}{|l|}{ BP } & \multirow{3}{*}{$\begin{array}{l}0.419 \\
0.011 *\end{array}$} \\
\hline Systolic BP (mean) & $168.67 \pm 10.88$ & $171.47 \pm 15.39$ & \\
\hline Diastolic BP (mean) & $112.40 \pm 7.01$ & $117.80 \pm 8.88$ & \\
\hline
\end{tabular}

Authors had almost equal number of primigravidae and multigravida. Most women belonged to low socioeconomic status $(96.7 \%$ for nifedipine and $100 \%$ for labetalol). Most Women (53\% vs 63.3\%) in both groups belonged to $37-40$ weeks gestational age. Very few women $(6.7 \%$ vs $10 \%)$ belonged to $<32$ weeks. The mean systolic BP in Labetalol group was $171.47 \pm 15.39$, and in nifedipine group was $168.67 \pm 10.88$. Table 2 shows that out of the 60 women studied, $18(60 \%)$ women had severe pre-eclampsia in the labetalol group compared to $26(86.7 \%)$ in the nifedipine group. In the labetalol $3(10 \%)$ women had imminent eclampsia compared to $2(6.7 \%)$ in the nifedipine group. In the labetalol group $9(30 \%)$ women had eclampsia while 2 $(6.7 \%)$ in nifedipine group.

Table 2: Comparison of SP/IE/E in the two study groups.

\begin{tabular}{|l|l|l|l|l|}
\hline \multirow{2}{*}{ SP/E } & Labetalo & \multicolumn{3}{|c|}{ Nifedipine } \\
\hline SP & No & \% & No & $\%$ \\
\hline E & 21 & 70.0 & 28 & 93.4 \\
\hline Total & 9 & 30.0 & 2 & 6.7 \\
\hline
\end{tabular}

*SP: severe pre-eclampsia, E: eclampsia 
In Table 3 subjects were categorised based on the number of doses required to control hypertension. In the nifedipine group $63.3 \%$ required only one dose compared to $36.6 \%$ in the labetalol group.

Only two women in the nifedipine group required maximum number of doses that is five doses. In the labetolol group 3 women did not reach the target blood pressure with five doses. They required cross over to nifedipine group as BP was not controlled $(\mathrm{P}$ value $=$ $0.044)$.

Table 3: Comparison of number of doses in the two study groups.

\begin{tabular}{|l|l|l|l|l|}
\hline \multirow{2}{*}{ No. of doses } & \multicolumn{2}{|c|}{ Labetalol } & \multicolumn{2}{c|}{ Nifedipine } \\
\hline 1 & No. & $\mathbf{\%}$ & No. & $\%$ \\
\hline 2 & 11 & 36.6 & 19 & 63.3 \\
\hline 3 & 9 & 30.0 & 5 & 16.7 \\
\hline 4 & 6 & 20.0 & 4 & 13.3 \\
\hline 5 & 1 & 3.3 & 0 & 0.0 \\
\hline$>5$ & 0 & 0.0 & 2 & 6.7 \\
\hline Total & 3 & 10.0 & 0 & 0 \\
\hline
\end{tabular}

Table 4 depicts the primary outcome which was the time taken to reach the target blood pressure. Patients receiving oral nifedipine achieved the therapeutic blood pressure goal in 20 minutes - $63.3 \%$ as compared with $36.6 \%$ in those receiving labetalol which was statistically significant $(\mathrm{P}=0.048)$.

Table 4: Comparison of time (min) taken to achieve the target blood pressure in the two study groups.

\begin{tabular}{|l|l|l|l|l|}
\hline \multirow{2}{*}{ Duration (min) } & \multicolumn{2}{|c|}{ Labetalol } & \multicolumn{2}{c|}{ Nifedipine } \\
\cline { 2 - 5 } & No. & $\%$ & No. & $\%$ \\
\hline 20 minutes & 11 & 36.6 & 19 & 63.3 \\
\hline 40 minutes & 9 & 30.0 & 5 & 16.7 \\
\hline 60 minutes & 6 & 20.0 & 4 & 13.3 \\
\hline 80 minutes & 1 & 3.3 & 0 & 0.0 \\
\hline 100 minutes & 0 & 0.0 & 2 & 6.7 \\
\hline >100 minutes & 3 & 10.0 & 0 & 0.0 \\
\hline Total & 30 & 100.0 & 30 & 100.0 \\
\hline
\end{tabular}

It was noted that $10 \%$ of patients needed more than 100 minutes while no patients in nifedipine group took more than 100 minutes to achieve the target blood pressure. The median time to achieve the target blood pressure was $32.0 \pm 18.64$ minutes (mean $\pm \mathrm{SD}$ ) in nifedipine group as compared with $37.04 \pm 16.36$ minutes in those receiving labetalol $(\mathrm{P}=0.002)$.

In Table 5 the duration of labour in the two groups remained almost similar in both groups (37.04 vs 32). It was observed that giving Injection $\mathrm{MgSO} 4$ simultaneously with the nifedipine did not cause prolonged labour.
Table 5: Duration of labour in the two study groups.

\begin{tabular}{|l|c|c|c|}
\hline $\begin{array}{l}\text { Duration of } \\
\text { labour }\end{array}$ & Group LAB & Group NIF & $\begin{array}{l}\text { P } \\
\text { value }\end{array}$ \\
\hline Mean \pm SD & $37.04 \pm 16.36$ & $32.00 \pm 18.66$ & 0.285 \\
\hline
\end{tabular}

Table 6 represents that parturients in both study groups had multiple side effects. Overall the incidence of adverse effects was more in nifedipine group when compared to labetalol group ( $20 \%$ vs $10 \%$ in labetalol group) which was not statistically significant.

Table 6: Comparison of adverse drug reactions in the two study groups.

\begin{tabular}{|c|c|c|c|c|}
\hline \multirow{2}{*}{ ADR } & \multicolumn{2}{|c|}{ Labetalol $(n=30)$} & \multicolumn{2}{|c|}{ Nifedipine $(n=30)$} \\
\hline & No. & $\%$ & No. & $\%$ \\
\hline No & 27 & 90.0 & 24 & 80.0 \\
\hline Yes & 4 & 13.3 & 6 & 20.0 \\
\hline Headache & 0 & 0.0 & 2 & 6.7 \\
\hline Sweating & 1 & 3.3 & 0 & 0.0 \\
\hline Tachycardia & 0 & 0.0 & 4 & 13.3 \\
\hline Vomiting & 3 & 10 & 0 & 0.0 \\
\hline
\end{tabular}

There were no instances of maternal death, cerebrovascular accident or severe acute renal failure necessitating dialysis. Only $3.3 \%$ of patients in labetalol group had urine output $<500 \mathrm{ml}$ which was not statistically significant. No parturient in nifedipine group had urine output $<500 \mathrm{ml}$. Table VII demonstrates that the babies requiring NICU admission were equal in both the study groups. The most common causes for NICU admission were for low birth weight and pre-term care. There was one neonatal death. The cause of death was respiratory distress syndrome. Two babies in labetalol group had APGAR at $5 \mathrm{~min}<7$.

Table 7: Perinatal outcomes in the two study groups.

\begin{tabular}{|l|l|l|l|l|}
\hline \multirow{2}{*}{ Complications } & Labetalol (30) & Nifedipine (30) \\
\hline NICU & No. & $\mathbf{\%}$ & No. & $\%$ \\
\hline Neonatal death & 15 & 53.3 & 15 & 50.0 \\
\hline APGAR at 5 min $<7$ & 2 & 3.3 & 0 & 0.0 \\
\hline Preterm & 4 & 13.3 & 0 & 0 \\
\hline Both & 3 & 10 & 2 & 6.7 \\
\hline
\end{tabular}

\section{DISCUSSION}

There has been a general consensus that blood pressure greater than $170 / 110 \mathrm{mmHg}$ requires treatment in the maternal interest, although this is not supported by randomised trials. ${ }^{15}$

The Cochrane review on drugs for the treatment of very high blood pressure in pregnancy concluded that until better evidence is available, the choice of antihypertensive should depend on the clinician's 
experience and familiarity with a particular drug, and on what is known about adverse effects. ${ }^{6}$

On performing a search in PubMed authors found that there were two RCT s (Vermilion et al, IA Raheem et al) similar to present study. ${ }^{16,17}$

The principal finding of IA Raheem et al was that the time taken to achieve the target blood pressure was almost the same with both drugs (45 min for labetalol and $30 \mathrm{~min}$ for nifedipine). The findings of present study were similar to Vermillion et al study, that is nifedipine is more rapidly effective and requires fewer dosing. Vermillion's study used higher oral nifedipine doses (10 $\mathrm{mg}$ initially, then $20 \mathrm{mg}$ for a further four doses, as required); IA Raheem et al used a flat $10 \mathrm{mg}$ nifedipine dose throughout. Authors used $20 \mathrm{mg}$ initially, then further $10 \mathrm{mg}$ for 4 doses and an intravenous labetalol regimen with a maximum dose of $300 \mathrm{mg}$ (which is identical to our regimen). However, according to NHBEP (National High Blood Pressure Education Programme) maximum dose of labetalol is $220 \mathrm{mg}$. Cross over was seen in $10 \%$ of our patients randomized to labetalol. $20 \%$ of patients in both groups in IA Raheem et al study needed cross over, where as in Vermillion's study there were no cross overs. In the subset of patients enrolled, $53.3 \%$ of babies needed NICU admission most of which were for preterm care $(23.3 \%$ in labetalol group and $13.4 \%$ in nifedipine group). There was one neonatal death due to respiratory distress syndrome. The 5-minute Apgar scores of $<7$ was seen in $6.6 \%$ in the labetalol group and none in nifedipine group, there were no fetal heart rate abnormalities. In Vermillion et al, Raheem et al study there were no observed differences in the occurrence of umbilical artery $\mathrm{pH}$ values of <7.0, 5-minute APGAR scores of $<7$, or fetal heart rate abnormalities.

All our patients and IA Raheem et al study was undelivered at enrolment, whereas Vermillion included postpartum subjects: this is an important difference as all our patients and more than two-thirds of the subjects of IA Raheem et al had their delivery expedited very shortly after achieving blood pressure control. There were no other major adverse effects attributed to either of the drug regimens. Our data supports the RCTs which opine that oral nifedipine and intravenous labetalol are suitable first line antihypertensives for hypertensive emergencies in pregnancy. ${ }^{18-20}$ In Vermillion's study a significant decrease in heart rate for labetalol and non-significant increase for nifedipine was noted; IA Raheem et al found a significant increase in heart rate for nifedipine and nonsignificant decrease for labetalol. However, authors did not observe changes in the maternal heart rate in any of the cases.

As most patients $(81.48 \%$ in labetalol vs $60 \%$ in nifedipine) received magnesium sulphate and were on Pritchard or single dose regimen at entry, it is difficult to determine exactly how much of the side effects noted were a result of the nifedipine and how much were the result of magnesium sulphate therapy. Authors have to consider the possible interaction between antihypertensive agents and magnesium sulphate. There are case reports of severe hypotension neuromuscular blockade, and symptomatic hypocalcaemia when nifedipine was used concurrently with magnesium sulphate infusion in hypertensive pregnancies. ${ }^{21-24}$ Clinically it would be difficult to remove these factors from our treatment plan for severely preeclamptic women. Therefore, in spite of potential confounding factors, the clinical applicability of our data appears appropriate.

In Vermillion et al study patients receiving nifedipine experienced a significant increase in urine output compared with the women receiving labetalol. As early as one hour after initial dosing, patients receiving nifedipine demonstrated urine output volumes twice those of patients receiving labetalol. This increase in urine output persisted at least 24 hours after initial dosing. Authors could not make any comment on the urine output as authors measured only the total urine output. Raheem et al also has not made any comment on urine output. Severe pre-eclampsia and eclampsia are confounding variables as urine output may be decreased because of acute severe hypertension. It is not possible to differentiate if it is due to the drug.

According to present study it was found that oral nifedipine and intravenous labetalol were both effective in controlling severe hypertension in pregnancy. It was found that nifedipine took a shorter time $(32.0 \pm 18.64$ min) and fewer doses (1 dose) to achieve the target blood pressure. The difference was statistically significant.

\section{CONCLUSION}

Authors found that nifedipine was a better drug than labetalol with a similar side effect profile. Nifedipine achieved the therapeutic blood pressure goal more rapidly and with fewer doses than labetalol. The favourable factors of nifedipine were rapid onset, long action, oral bio availability, and infrequent side effects. Lastly nifedipine was more cost effective than labetalol. The power of the study does not allow us to make definitive conclusions regarding the safety of either study medication. However, the limitation of present study was the small sample size so more robust studies are required to incorporate the findings into clinical practice.

\section{Funding: No funding sources \\ Conflict of interest: None declared}

Ethical approval: The study was approved by the Institutional Ethics Committee

\section{REFERENCES}

1. Witlin AG, Sibai BM. Magnesium sulphate therapy in preeclampsia and eclampsia. Obstet Gynecol. 1998;92(5):883-9. 
2. Sahin G, Gulmezoglu AM. Incidence morbidity and mortality of pre-eclampsia and eclampsia. Geneva Foundation for Medical Education and Research 2003.

3. Rey E, LeLorier J, Burgess E, Lange IR, Leduc L. Report of the Canadian Hypertension Society Consensus Conference: 3. Pharmacologic treatment of hypertensive disorders in pregnancy. CMAJ 1997:157(9):1245-54.

4. Report of the National High Blood Pressure Education Program Working Group on High Blood Pressure in Pregnancy. Am J Obstet Gynecol 2000;183(1):S1-22.

5. Brown MA, Hague WM, Higgins J, Lowe S, McCowan L, Oats J, et al. The detection, investigation and management of hypertension in pregnancy: executive summary. Aust NZJ Obstet Gynaecol. 2000;40(2):133-8.

6. Duley L, Henderson-Smart DJ, Meher S. Drugs for treatment of very high blood pressure during pregnancy. Cochrane Database of Systematic Reviews. 2006(3).

7. Cutler JA. Calcium-channel blockers for hypertension-uncertainty continues. N Eng J Med 1998;338:679-81

8. Ben Ami M, Giladi Y, Shalev E. The combination of magnesium sulphate and nifedipine: a cause of neuromuscular blockade. $\mathrm{Br} \mathrm{J}$ Obstet Gynaecol 1994;101(3):262-3.

9. Snyder SW, Cardwell MS. Neuromuscular blockade with magnesium- sulfate and nifedipine. Am J Obstet Gynecol. 1989;161(1):35-6.

10. Stevens TP, Guillet R. Use of glucagon to treat neonatal low-output congestive heart failure after maternal labetalol therapy. J Pediatr 1995;127(1):151-3.

11. Mackay AP, Berg CJ, Atrash HK. Pregnancy-related mortality from preeclampsia and eclampsia. Obstet Gynecol 2001;97(4):533-8.

12. Waugh J, Bell SC, Kilby M, Seed P, Blackwell C, Shennan AH, et al. Optimal bedside urinalysis for the detection of proteinuria in hypertensive proteinuria: a study of diagnostic accuracy? BJOG2005:112(4):412-17.

13. Waugh JJ, Clark TJ, Divakaran TG, Khan KS, Kilby MD. Accuracy of urinalysis dipstick techniques in predicting significant proteinuria in pregnancy. Obstet Gynecol. 2004;103(4):769-77.

14. Phelan LK, Brown MA, Davis GK, Mangos G.A prospective study of the impact of automated dipstick urinalysis on the diagnosis of pre-eclampsia. Hypertens Pregnancy 2004;23(2):135-42.

15. Martin JN Jr, May WL, Magann EF, Terrone DA, Rinehart BK, Blake PG. Early risk assessment of severe pre-eclampsia: admission battery of symptoms and laboratory tests to predict likelihood of subsequent significant maternal morbidity. Am J Obstet Gynecol 1999;180(6):1407-14

16. Vermillion ST, Scardo JA, Newman RB, Chauhan SP. A randomized, double-blind trial of oral nifedipine and intravenous labetalol in hypertensive emergencies of pregnancy. AJOG.1999;181(4):8626.

17. Raheem IA, Saaid R, Omar SZ, Tan PC. Oral nifedipine versus intravenous labetalol for acute blood pressure control in hypertensive emergencies of pregnancy: a randomised trial. BJOG: Int J Obstet Gynaecol. 2012;119(1):78-85.

18. Sibai BM: Diagnosis and management of gestational hypertension and preeclampsia. Obstet Gynecol 2003;102(1):181.

19. National Institute of Health and Clinical Excellence. Hypertension in Pregnancy, The management of hypertensive disorders during pregnancy. Clinical guidelines CG107 Issued: August 2010. Available at http://guidance.nice.org.uk/CG107. Last accessed 26 December 2010.

20. The Royal College of Obstetricians and Gynaecologists, United Kingdom. Green Top Guideline No. 10 (A). The management of severe pre-eclampsia/eclampsia. March 2006. Available at online www.rcog.org.uk/files/rcog-corp/upload files/GT10a Management Preeclampsia 2006.pdf.

21. Scardo JA, Hogg BB, Newman RB. Favorable hemodynamic effects of magnesium sulphate in preeclampsia. Am J Obstet Gynecol 1995;173(4):1249-53.

22. Waisman GD, Mayorga LM, Camera MI, Vignolo CA, Martinotti A. Magnesium plus nifedipine: potentiation of hypotensive effect in preeclampsia? Am J Obstet Gynecol. 1988;159(2):308-9.

23. Ben-Ami M, Giladi Y, Shalev E. The combination of magnesium sulphate and nifedipine: a cause of neuromuscular blockade. $\mathrm{Br} \quad \mathrm{J}$ Obstet Gynaecol1994;101(3):262-3.

24. Snyder SW, Cardwell MS. Neuromuscular blockade with magnesium sulphate and nifedipine. Am J Obstet Gynecol1989;161(1):35-6.

Cite this article as: Krishna K, Shailaja N, Bhat BS, Krishna L, Namrata. A randomized cross over trial of oral nifedipine and intravenous labetalol in pregnant women with severe pre-eclampsia and eclampsia. Int J Reprod Contracept Obstet Gynecol 2019;8:921-6. 